\title{
Optimization of Digital Image Processing Method to Improve Smoke Opacity Meter Accuracy
}

\author{
Dwi Sudarno Putra ${ }^{\#}$, Donny Fernandez ${ }^{\#}$, Wagino ${ }^{\#}$ \\ \# Department of Automotive Engineering, State University of Padang, Indonesia \\ E-mail:dwisudarnoputra@gmail.com,fernandez_79@yahoo.co.uk,gino_اmda@yahoo.com
}

\begin{abstract}
One of the parameters of exhaust emission testing on diesel engines is the level of smoke opacity. If the opacity is high then the emission quality is bad. The instrument for measuring smoke opacity is called Smoke Opacity Meter. The commonly used basic concept to measure smoke density is by utilizing a light sensor (optical sensor). Development of Smoke Opacity Meter applies the concept of Digital Image Processing. Even though it has initially begun, the measurement result is yet as perfect as Optical Sensor Concept. Therefore, this paper describes on how to implement the Digital Image Processing Method in processing the smoke opacity video data.
\end{abstract}

Keywords — Digital Image Processing, Smoke Opacity Meter, Automotive Measurement Tool.

\section{INTRODUCTION}

Vehicle inspection process as means of transportation is periodically conducted. It begins before mass production, before being issued by the manufacturers, up to being used by the customers. It is for the safety of human being who take this mean of transportation.

Nevertheless it is benefitful for human, this vehicle machine has negative impact as well. Consequently, it is done by minimizing this matter through vehicle testing process. One of the negative impacts and is the most popular issues is the pollution impact resulted from vehicle exhaust emission. Generally, the vehicle that produces exhaust emission is oilfueled engine. There are two types of engine used, they are gasoline engine and diesel engine. Pollution or emission produced by these two engines has different content, therefore their measuring instrument is different as well.

In line with technology development, vehicle engines are designed to be more eco-friendly, and in order to support it some regulations are established by government. International emission standard is commonly known as EURO STANDARD. Meanwhile, in national level there is a decree issued by Ministry of Environtment (KLH).

In order to guarantee that the testing on exhaust emission is valid, thus emission measuring instrument is developed in accordance with the appropriate standard mentioned above. In addition, this instrument should have a good precision.
This article is trying to show an optimization of Digital Image Processing (DIP) method used to test the smoke of diesel engine. Result of previous study viewes that DIP can be utilized to measure the smoke opacity level of diesel engine [1]. This article focuses on DIP optimization in obtaining better measuring result than before. The method is by multiplying the tested images object taken from video data.

\section{THEORY FOUNDATION AND RESEARCH METHOD}

Several scientific studies and basic theory applied in this paper are smoke opacity, type of measuring instrument for smoke opacity, DIP and several DIP studies related to smoke.

\section{A. Smoke Opacity}

Smoke opacity is a measurement to quantify the density of smoke particle in the air that can absorp amount of light beam so that the light obscured by smoke. Smoke density is measured in percentage between 0 up to 100 percent percent [2]. Hence, this paper describes the smoke density of diesel engine vehicle.

\section{B. Measurement Instrument of Smoke Opacity}

Generally, measuring instrument for smoke opacity conducted by utilizing a light beam source and a receptor. As seen in Figure 1, if light intensity received by the receptor is bigger, thus smoke opacity is smaller (reaching 0\%). However, when the receptor receives a small amount of light beam intensity, thus smoke opacity is big (reaching $100 \%$ ). 


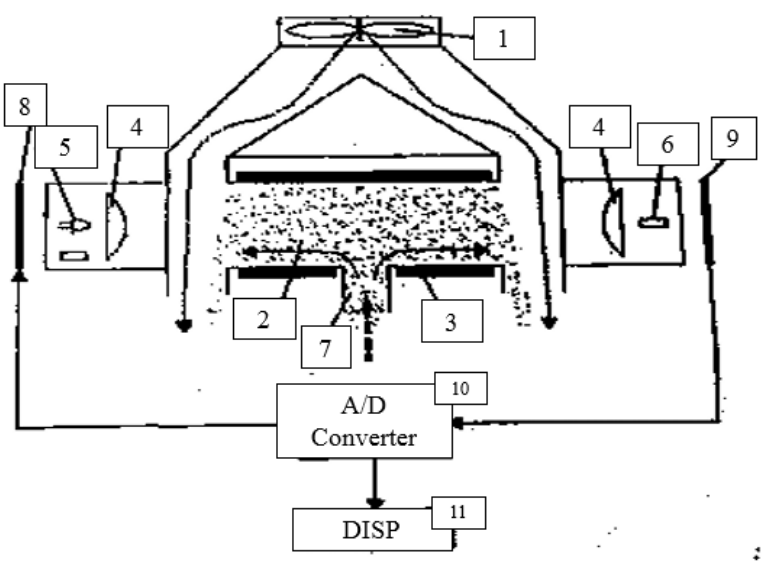

Fig. 1. Working principles of existing smoke opacity measuring instrument (Opacity Smoke meter OPA - 101)

Parts on a smoke opacity measuring instrument with Light Source Method and Light Receptor, OPA 101 type.

1.Purge Fan.

2.Sampling-shell.

3.Sampling-shell constant temperature purpose heater.

4.Concentrating light lens.

5.Light source (Green LED).

6.Light sensor (Photodiode).

7.Collecting gas inhaling hole.

8.Light source control circuit.

9.Signal input and Analyzing circuit.

10.AD Converter circuit.

11.Displaying part.

\section{Digital Image Processing}

Digital images are electronic snapshots taken from a scanned from documents or a scene such as photographs, manuscripts, printed texts, and artwork [4]. Digital Image Processing is a digital process of picture/ image, and formed in matrix arrangement. Matrix is an array of numbers arranged into certain rows and colums. Image matrix component contains of numbers with particular value representing image on each pixel as shown in Figure 2.

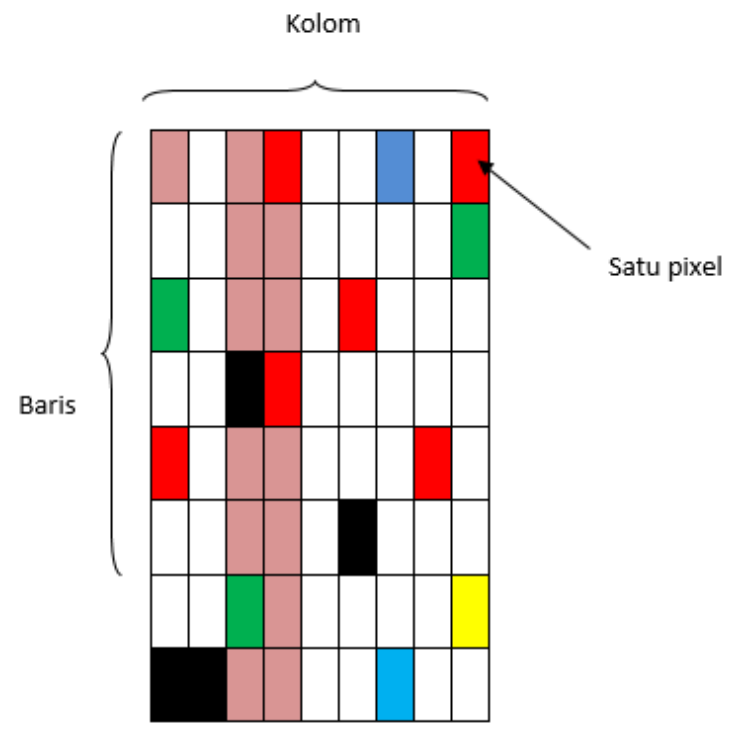

Fig. 2. Matrix Illustration in Digital Images

\section{Previous Study}

There have been many studies on smoke images. Some of them expose that the smoke color is grey [3]. In contrast, in other studies found that smoke detection can be done by accumulating moving images model in order to find the smoke characteristic [4]. To add, previous study conducted by the writer has successfully designed a smoke opacity measuring instrument on diesel engine utilizing DIP method. Despite the result of it has yet been maximal [1].

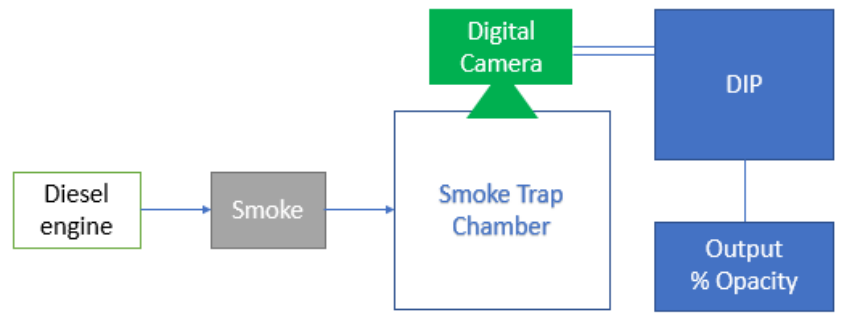

Fig. 3. Study implementation diagram

The scheme in collecting the smoke data on diesel engine vehicle follows the sequences as presented in Figure 3. Main data is taken from sample-shell. This space is designed to such an extent resembling the one in Opacity smoke meter OPA 101 by changing the data collector from Light Source to Light Sensor, and turned it into indoor light and digital camera.

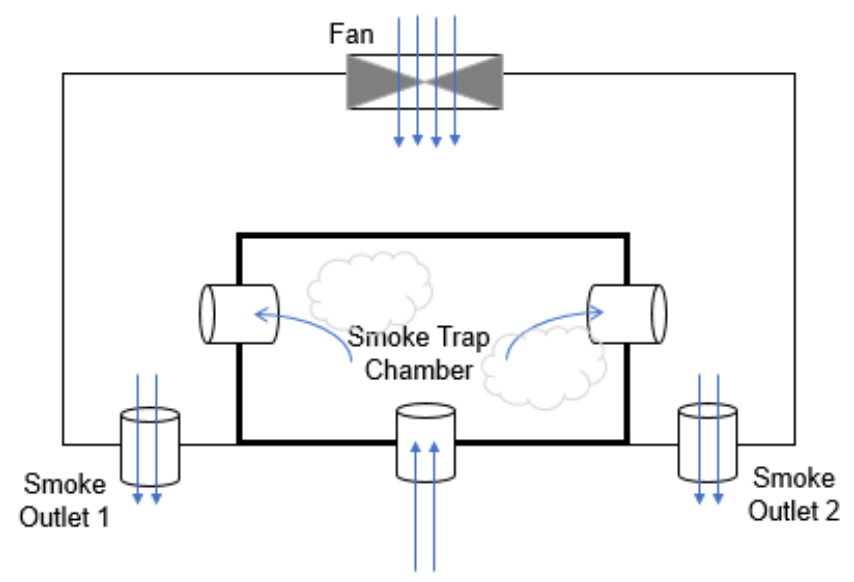

Smoke Inlet

Fig 4. Developed smoke opacity meter design

Camera is utilized to collect smoke image data, within this article, it is done by taking the video data. Then the data is extracted becoming several frames and processed using DIP [1], and finally averaged the reading result.

The algorithm of applied DIP process is as follow:

1. Collecting the data of smoke video record.

2. Initiating preliminary image as reference before the smoke gets inside.

3. Extracting video record data becoming image sequence in $n$ image amount.

4. Starting from the first image data to the $n$, and then

a. Reading DIP value on each image.

b. Saving the \% smoke opacity data.

5. Presenting the graphic.

6. Calculating the average value 


\section{RESUlt AND DISCUSSION}

The video data was successfully recorded using developed instrument. Then this data was extracted and processed utilizing DIP, and finally was averaged.

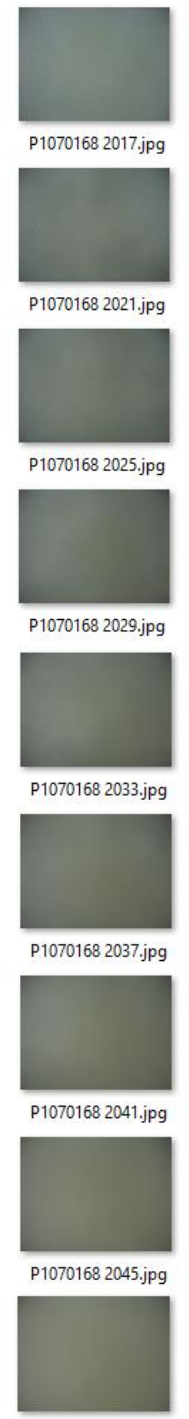

P1070168 2049.jpg

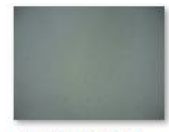

P1070168 2018.jpg

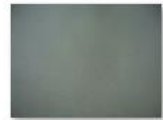

P1070168 2022.jpg

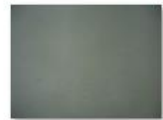

P1070168 2026.jpg

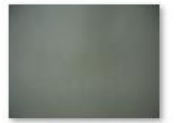

P1070168 2030.jpg

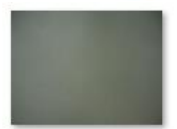

P1070168 2034.jpg
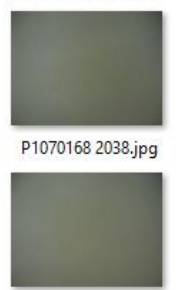

P1070168 2042.jpg

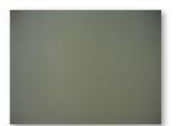

P1070168 2046.jpg

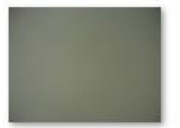

P1070168 2050.jpg
P1070168 2038.jpg

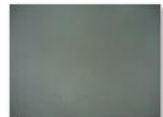

P1070168 2019.jpg

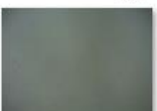

P1070168 2023.jpg

P1070168 2027.jpg

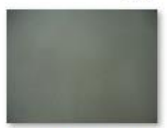

P1070168 2031.jpg

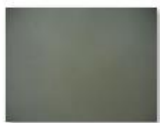

P1070168 2035.jpg

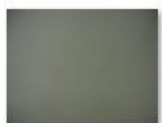

P1070168 2039.jpg

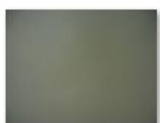

P1070168 2043.jpg

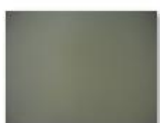

P1070168 2047.jpg

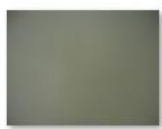

P1070168 2051.jpg

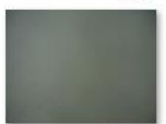

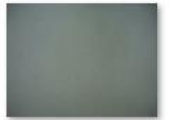

P1070168 2020.jpg

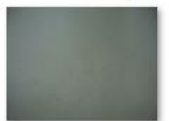

P1070168 2024.jpg

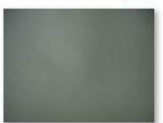

P1070168 2028.jpg

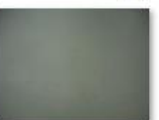

P1070168 2032.jpg

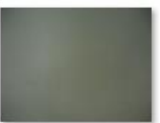

P1070168 2036.jpg

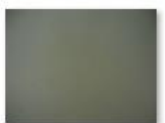

P1070168 2040.jpg

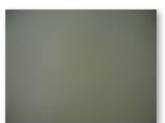

P1070168 2044.jpg

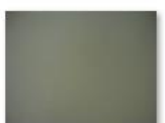

P1070168 2048.jpg

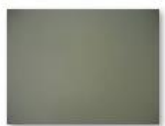

P1070168 2052.jpg
Fig 5. The sample of video extracting result

From the data processing and algorithm executing mentioned above, the data obtained was presented in Table 1.

Taken into account, through smoke opacity percentage value and graphic formed by the data, there were several important points could be considered.

First, developed algorithm was able to read the differences on several frames in more detail.

Second, developed algorithm was proven showing percentage increasing tendency when smoke opacity occured during engine acceleration process.
TABLE 1

EXECUtion RESUlt On SMOKe OPACITy PERCENTAge PROGRAM IN ACCORDANCE WITH FIGURE 5

\begin{tabular}{l|l|l|l}
\hline 15.9463 & 13.9873 & 21.1915 & 19.2885 \\
\hline 23.8845 & 19.7965 & 24.5474 & 21.7475 \\
\hline 25.9953 & 23.1323 & 26.9074 & 23.7068 \\
\hline 27.3945 & 23.5398 & 25.3495 & 22.6715 \\
\hline 25.5696 & 25.3667 & 26.9222 & 26.9851 \\
\hline 26.3782 & 27.4100 & 24.5471 & 26.7545 \\
\hline 24.8207 & 24.3120 & 25.0094 & 22.9198 \\
\hline 23.8575 & 22.7321 & 22.9262 & 22.2703 \\
\hline 21.5978 & 20.6676 & 20.0342 & 19.2419 \\
\hline Average = 23,3169\% & &
\end{tabular}

Furthermore, if the data was made into graphic, then the graffic was formed as seen in Figure 6.

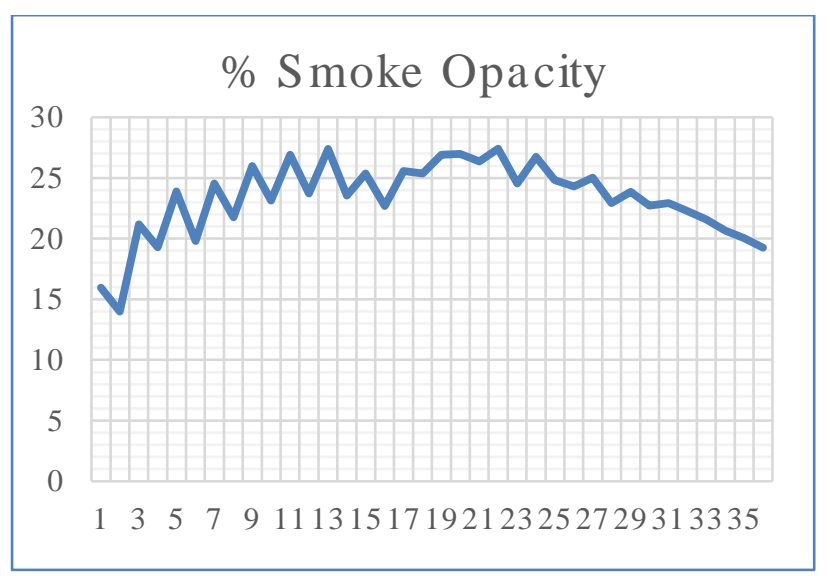

Fig. 6. The graphic of smoke opacity percentage (\%) value during acceleration

Despite, when comparing it with the existing data from the previous study [1], so that high percentage of acceleration using this algorithm was categorized far below the value provided by other measurement instruments which were able to reach up to $46.39 \%$ smoke opacity value. It was due to preliminary image initiation was based on earliest images. In contrast, the preliminary image in the previous study was images in white color.

\section{CONCLUSION}

Applied DIP method optimization in this paper generates evidence that video base analysis can elevate the reading process of smoke opacity.

\section{ACKNOWLEDGMENT}

First and most earnest gratitude to Padang State University, particularly to Unit for Research and Community Service (LP2M, UNP), for granting this study. 


\section{REFERENCES}

[1] D Fernandez, DS Putra, W Wagino, M Arif. (2017). "Implementasi Metode Digital Image Processing untuk Menguji Kepekatan Asap Kendaraan Motor Diesel” JIT Politeknik Kota Malang, vol 1, no 1,

[2] Granholm, Jennifer M. (2007). Diesel exhaust Emissions. New Jarsey : University of Wisconsin.
[3] C. Yu, J. Fang, J. Wang, and Y. Zhang, "Video fire smoke detection using motion and color features," Fire Technology, vol. 46, no. 3, pp. 651-663, July 2010.

[4] Amiri, D. M. (2011). Digital Image Proceessing, 5. 